\title{
A Case Series and Discussion on Surgical Treatment Strategy for Atypical Proximal Femoral Fractures Associated with Bisphosphonate Use
}

\author{
Brett Rocos ${ }^{1}$, Thomas Fleming ${ }^{1}$, Karen Harding ${ }^{2}$, Mehool Acharya ${ }^{2}$, Andrew Riddick ${ }^{2}$, Mike Kelly ${ }^{2}$ \\ 1. Orthopaedics, North Bristol National Health Service Trust, Bristol, GBR 2. Orthopaedic Surgery, North Bristol \\ National Health Service Trust, Bristol, GBR
}

Corresponding author: Brett Rocos, brettrocos@yahoo.co.uk

\begin{abstract}
The aim of this study was to determine the incidence of atypical femoral fractures in our local population, study their current outcomes and present a novel surgical strategy based on these data. Patients who received surgical fixation of an atypical pattern proximal femoral fracture over a four-year period were identified and followed up in the clinic until union, revision surgery or death.

The local incidence of atypical femoral fractures is 1.1 per 1000 per annum amongst patients receiving bisphosphonates. Twelve fixation procedures were carried out in 10 patients. Intra-operative reduction and nailing led to an average deformity of $8.5^{\circ}$ varus and $13^{\circ}$ apex anterior. Five cases required revision surgery. Fifty percent of primary procedures resulted in radiographic union within two years. We suggest that the lateral side of the fracture should be considered a primary nonunion. We advocate undertaking a wedge excision to correct the bone to a valgus morphology and stabilising with an intramedullary nail and a lateral tension plate. Multicentre studies are needed to demonstrate the efficacy of any particular approach.
\end{abstract}

Received 10/31/2018 Review began 11/05/2018 Review ended 11/26/2018 Published 12/02/2018

\section{(c) Copyright 2018}

Rocos et al. This is an open access article distributed under the terms of the Creative Commons Attribution License CC-BY 3.0., which permits unrestricted use, distribution, and reproduction in any medium, provided the original author and source are credited.
Categories: Emergency Medicine, Internal Medicine, Orthopedics

Keywords: trauma, geriatrics, resuscitation, blood transfusion

\section{Introduction}

Bisphosphonates are widely used for the treatment of osteoporosis and have reduced the incidence of fragility fractures by up to 53\% [1-2]. Since first identified by Odvina et al. in 2005, the association of longterm bisphosphonate use with atypical fractures of the proximal femur has become a concern [3-10], which led to the Medicines and Healthcare Products Regulatory Agency (MHRA) issuing safety updates in 2009 and 2011 regarding the prolonged use of bisphosphonates and the surveillance of patients taking the drugs over a long term [11]. Atypical femoral fractures are thought to occur due to bisphosphonates preventing the formation and action of osteoclasts, consequently preventing the normal remodelling of stress fractures with the effect of allowing propagation of the fracture line across the entire bone [6-7,12-13]. Histological analysis of the tissues taken from atypical femoral fractures has supported this theory by showing a paucity of osteoclasts within an immature new bone [14].

The diagnosis of atypical femoral fracture requires the injury to meet major and minor features. All major features must be satisfied, and although none of the minor features are required, they are strongly associated with the injury $[11,15-16]$. The incidence of bisphosphonate-associated fractures is thought to be approximately one per 1000 per annum, and the existing literature shows a high complication rate associated with treating these injuries, including nonunion, delayed union and metalwork failure requiring revision surgery [17-19]. The 2014 American Society of Bone and Mineral Research (ASBMR) task force identified the deficiencies in the management of these injuries and noted that no optimal surgical strategy has been described $[15,20]$.

The purpose of this study was to determine the incidence of these fractures in our population, study the clinical and radiological outcomes in our cohort and present a novel surgical strategy based on these data.

\section{Materials And Methods}

A retrospective cohort methodology was employed. Patients who were treated for an atypical proximal femoral fracture in our unit between $1^{\text {st }}$ March 2009 and $31^{\text {st }}$ March 2013 were identified from a prospectively collected orthogeriatric database (non-proprietary), wherein details regarding the atypical fractures are collected. Patients were excluded if the fracture was distal to the isthmus or they failed to survive to discharge from the outpatient follow-up. Data were correlated with the Trauma and Orthopaedic admission and procedure database (Bluespier Patient Manager v.8.0S, Bluespier International, Droitwich, UK) to ensure no relevant cases were absent from the analysis. The patients' clinical records and digitally 
stored investigations were reviewed to confirm the accuracy of the diagnosis and the treatment data. Preoperative radiographs were assessed in the orthopaedic multidisciplinary meeting to confirm the diagnosis of atypical proximal femoral fracture. Post-operative radiographs were reviewed in the same multidisciplinary meeting to determine the accuracy of reduction, type of fixation and any augmentation used. An independent consultant orthopaedic trauma surgeon who was blinded to the patients' medical and pharmacological history then subsequently reviewed each radiograph to confirm both the diagnosis and treatment characteristics.

Follow-up radiographs and clinical records were reviewed to determine progression to medial and lateral union. Union was defined by the presence of callus bridging the two fragments visible on orthogonal radiographs as assessed by both the consulting clinician and an independent, blinded consultant trauma surgeon. No clinical criteria for the union were set, although the absence of symptoms supported union when identified radiologically. Any failure of fixation or revision surgery was also noted.

\section{Results}

Within the catchment area of our unit, the latest data available (2012) show that 4490 patients had a diagnosis of osteoporosis, of which 3395 underwent bisphosphonate therapy [21]. This gives rise to an expected annual incidence of atypical femoral fractures of 3.3 fractures per year presenting to the trauma service.

Seventeen primary operations for atypical femoral fractures were carried out for 15 patients between $1^{\text {st }}$ March 2009 and $31^{\text {st }}$ March 2013, representing 1\% of 1831 proximal femoral reconstructive operations performed during that period in our tertiary trauma unit. The calculated incidence of atypical femoral fractures in our region is 1.1 per 1000 per annum amongst patients taking bisphosphonates. This is comparable to the established incidence of 1:1000 per year published by Schilcher et al. in 2009 [17].

Three procedures were excluded due to the fracture being distal to the isthmus. Two were excluded as they were prophylactic procedures for the impending fractures. The 12 remaining procedures were carried out in 10 patients. Nine patients were female with a mean age of 71 years (Table 1 ). 


\section{Cureus}

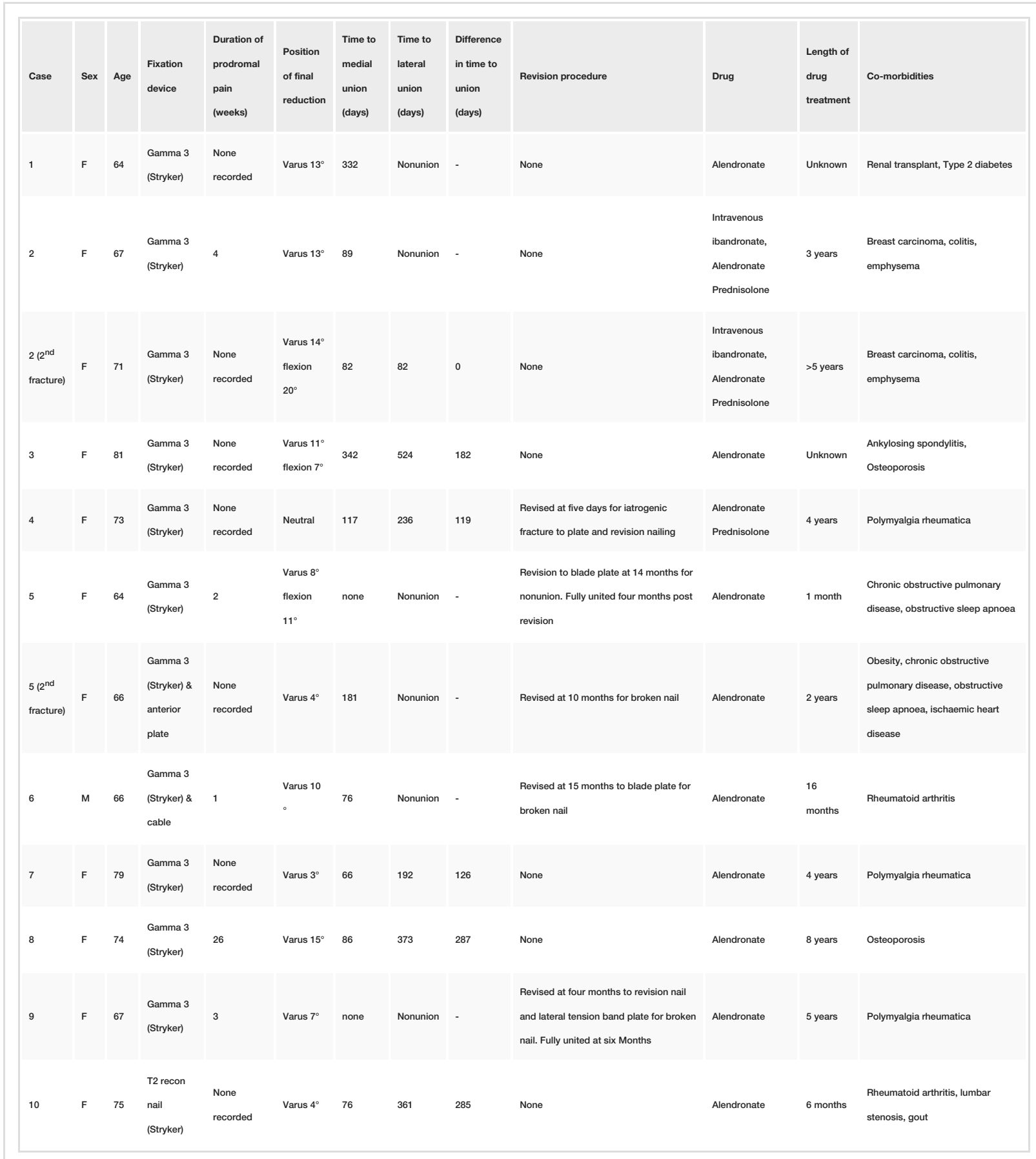

TABLE 1: The demographics, clinical details and surgical results of patients with atypical proximal femoral fractures treated in our unit between March 1, 2009 and March 31, 2013.

Seven cases required an open approach to achieve a reduction. Anatomical reduction was achieved in each case, giving rise to a femur with an average of $8.5^{\circ}$ varus deformity. Three patients showed an average apex anterior malreduction of $13^{\circ}$ visible on the lateral radiograph.

Fifty percent of the primary procedures resulted in radiographic evidence of both medial and lateral union within a two-year follow-up. In those patients who united both medially and laterally, the lateral union took an average of 167 days longer than the medial side (range: 0-287 days).

Five revision procedures were required: one for nonunion, three for the failure of metalwork and a single case for iatrogenic periprosthetic fracture occurring at the primary procedure. The details of revision surgery can be seen in Table 1 . 


\section{Discussion}

The literature describes the prevalence of atypical femoral fractures as 0.5-1:1000 per annum, a figure confirmed in our own series [17,22-24]. It is an uncommon injury and each trauma service will see only a few cases every year. The present literature suggests managing these injuries with anatomical reduction and cephalo-medullary nail fixation [25]. Our results echo those of a similar case series, showing a low rate of union and a high re-operation rate with this treatment strategy [26-29]. This group of patients tends to have multiple co-morbidities (the median American Society of Anesthesiologists (ASA) Physical Status grade in this study was three). The development of a surgical strategy that reduces the reoperation rate would, therefore, be desirable.

Based on the data from this study, we hypothesize that the femur deforms into varus because of the inhibited physiology leading to the propagation of the lateral cortical stress responses until a fracture results. This then fails to unite due to the continued action of bisphosphonates and the adjacent cortical reaction producing the typical beaking $[20,30]$. This is demonstrated by the femora in this cohort showing a mean varus deformity of $8.5^{\circ}$ at the time of fracture. The non-united stress fractures continue to be subjected to a varus moment causing their propagation through the remaining bone to complete the femoral fracture.

We suggest that the lateral side of the atypical proximal femoral fractures should be considered a primary nonunion and dealt with as such $[11,18]$. By contrast, the medial cortical break behaves like an acute fracture, with haematoma and intramembranous ossification. This suggests that this lateral portion of the fracture represents a chronic, sclerotic, nonunion with poor healing potential. The fracture propagates to completion when the remaining intact bone becomes insufficient to support the patient's weight [6-7,12-13]. Furthermore, it is likely that the cortical defect propagates over a long period (increasing varus appearance radiographically) prior to eventual fracture completion. This is reflected in that half of our cohort who complained of prodromal thigh pain for up to 18 months.

The $42 \%$ re-operation rate in our series shows that the currently accepted fixation techniques are inadequate. At best, they are only able to correct alignment back to the pre-existing varus deformity present just prior to fracture completion. This does not address the poor mechanical environment, particularly in the face of impaired biology meaning that the lateral healing is at best very delayed putting the implant at a high risk of failure before union occurs.

We advocate a surgical strategy that anticipates the impaired biology and addresses the inadequate mechanical environment. This is achieved by undertaking a wedge excision to remove the sclerotic lateral margin and correcting the bone to a valgus morphology. Stabilization is then achieved using an intramedullary nail and lateral tension plate positioned just posterior to the nail on the lateral view at the level of the fracture (Figure 1). This strategy optimizes the mechanical environment creating a situation where the mechanics of the fracture are in optimal circumstances for healing. This strategy will now be adopted in our unit as a standard approach to this injury and results will be reported on when available.
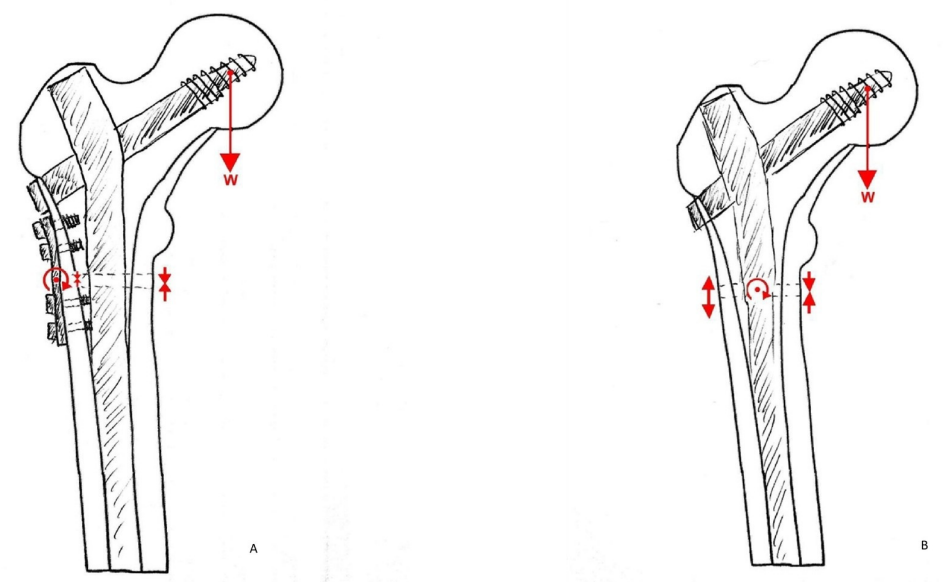

FIGURE 1: Forces applied across an atypical fracture following traditional and novel fixation techniques

The red arrows indicate the direction of force applied by the body weight $(w)$ and the resultant forces across the fracture caused by the fixation technique.

A) Cephalomedullary nail alone caused distraction at the lateral side of the fracture, increased if the natural varus is not corrected. B) With the addition of a lateral tension band plate, wedge excision of the lateral 


\section{Conclusions}

Atypical femoral fractures are uncommon and difficult to manage reproducibly. Current techniques have a $30-40 \%$ incidence of re-operation. We therefore now advocate of an initial surgical management strategy that uses a valgising wedge osteotomy to correct the evolved varus morphology and improve the mechanics of the final construct. As this is a rare injury, multicentre studies are needed to demonstrate the efficacy of any particular approach.

\section{Additional Information \\ Disclosures}

Human subjects: Consent was obtained by all participants in this study. Animal subjects: All authors have confirmed that this study did not involve animal subjects or tissue. Conflicts of interest: In compliance with the ICMJE uniform disclosure form, all authors declare the following: Payment/services info: All authors have declared that no financial support was received from any organization for the submitted work. Financial relationships: All authors have declared that they have no financial relationships at present or within the previous three years with any organizations that might have an interest in the submitted work. Other relationships: All authors have declared that there are no other relationships or activities that could appear to have influenced the submitted work.

\section{References}

1. Black DM, Thompson DE, Bauer DC, et al.: Fracture risk reduction with alendronate in women with osteoporosis: the fracture intervention trial. J Clin Endocrinol Metab. 2000, 85:4118-4124. 10.1210/jcem.85.11.6953

2. Bilezikian JP: Efficacy of bisphosphonates in reducing fracture risk in postmenopausal osteoporosis . Am J Med. 2009, 122:14-21. 10.1016/j.amjmed.2008.12.003

3. Odvina CV, Zerwekh JE, Rao DS, Maalouf N, Gottschalk FA, Pak CY: Severely suppressed bone turnover: a potential complication of alendronate therapy. J Clin Endocrinol Metab. 2005, 90:1294-1301. 10.1210/jc.2004-0952

4. Goh SK, Yang KY, Koh JS, Wong MK, Chua SY, Chua DT, Howe TS: Subtrochanteric insufficiency fractures in patients on alendronate therapy. J Bone Joint Surg Br. 2007, 89:349-353. 10.1302/0301-620x.89b3.18146

5. Gedmintas L, Solomon DH, Kim SC: Bisphosphonates and risk of subtrochanteric, femoral shaft, and atypical femur fracture: a systematic review and meta-analysis. J Bone Miner Res. 2013, 28:1729-1737. 10.1002/jbmr.1893

6. Neviaser AS, Lane JM, Lenart BA, Edobor-Osula F, Lorich DG: Low-energy femoral shaft fractures associated with alendronate use. J Orthop Trauma. 2008, 22:346-350. 10.1097/BOT.0b013e318172841c

7. Kwek EB, Goh SK, Koh JS, Png MA, Howe TS: An emerging pattern of subtrochanteric stress fractures: a long-term complication of alendronate therapy?. Injury. 2008, 39:224-231. 10.1016/j.injury.2007.08.036

8. Odvina CV, Levy S, Rao S, Zerwekh JE, Rao DS: Unusual mid-shaft fractures during long-term bisphosphonate therapy. Clin Endocrinol (Oxf). 2010, 72:161-168. 10.1111/j.1365-2265.2009.03581.x

9. Sayed-Noor AS, Sjoden GO: Subtrochanteric displaced insufficiency fracture after long-term alendronate therapy-a case report. Acta Orthop. 2008, 79:565-567. 10.1080/17453670710015580

10. Jo YR, Kim HW, Moon SH, Ko YJ: A case report of long-term bisphosphonate therapy and atypical stress fracture of bilateral femur. Ann Rehabil Med. 2013, 37:430-432. 10.5535/arm.2013.37.3.430

11. Bisphosphonates: atypical femoral fractures . (2014). Accessed: November 5, 2018: http://www.gov.uk/drugsafety-update/bisphosphonates-atypical-femoral-fractures.

12. Mashiba T, Mori S, Burr DB, Komatsubara S, Cao Y, Manabe T, Norimatsu H: The effects of suppressed bone remodeling by bisphosphonates on microdamage accumulation and degree of mineralization in the cortical bone of dog rib. J Bone Miner Metab. 2005, 23:36-42. 10.1007/BF03026321

13. Girgis CM, Seibel MJ: Atypical femur fractures: a review of the evidence and its implication to clinical practice. Ther Adv Musculoskelet Dis. 2011, 3:301-314. 10.1177/1759720x11416270

14. Kajino Y, Kabata T, Watanabe K, Tsuchiya H: Histological finding of atypical subtrochanteric fracture after long-term alendronate therapy. J Orthop Sci. 2012, 17:313-318. 10.1007/s00776-011-0085-8

15. Shane E, Burr D, Ebeling PR, et al.: Atypical subtrochanteric and diaphyseal femoral fractures: report of a task force of the American Society for Bone and Mineral Research. J Bone Miner Res. 2010, 25:2267-2294. 10.1002/jbmr.253

16. Assessment report for bisphosphonates containing medicinal products . (2011). Accessed: November 27, 2018: https://www.ema.europa.eu/documents/referral/assessment-report-bisphosphonates-containingmedicinal-products_en.pdf.

17. Schilcher J, Aspenberg P: Incidence of stress fractures of the femoral shaft in women treated with bisphosphonate. Acta Orthop. 2009, 80:413-415. 10.3109/17453670903139914

18. Giusti A, Hamdy NA, Papapoulos SE: Atypical fractures of the femur and bisphosphonate therapy: A systematic review of case/case series studies. Bone. 2010, 47:169-180. 10.1016/j.bone.2010.05.019

19. Thompson RN, Phillips JR, McCauley SH, Elliott JR, Moran CG: Atypical femoral fractures and bisphosphonate treatment: experience in two large United Kingdom teaching hospitals. J Bone Joint Surg Br. 2012, 94:385-390. 10.1302/0301-620x.94b3.27999

20. Shane E, Burr D, Abrahamsen B, et al.: Atypical subtrochanteric and diaphyseal femoral fractures: second 


\section{Cureus}

report of a task force of the American Society for Bone and Mineral Research. J Bone Miner Res. 2014, 29:123. 10.1002/jbmr.1998

21. Public Health Profiles. (2015). Accessed: November 5, 2018: http://fingertips.phe.org.uk/profile/generalpractice/data.

22. Schilcher J, Michaelsson K, Aspenberg P: Bisphosphonate use and atypical fractures of the femoral shaft . N Engl J Med. 2011, 364:1728-1737. 10.1056/NEJMoa1010650

23. Schilcher J, Koeppen V, Aspenberg P, Michaelsson K: Risk of atypical femoral fracture during and after bisphosphonate use. N Engl J Med. 2014, 371:974-976. 10.1056/NEJMc1403799

24. Schilcher J, Koeppen V, Aspenberg P, Michaelsson K: Risk of atypical femoral fracture during and after bisphosphonate use. Acta Orthop. 2015, 86:100-107. 10.3109/17453674.2015.1004149

25. Das De S, Setiobudi T, Shen L: A rational approach to management of alendronate-related subtrochanteric fractures. J Bone Joint Surg Br. 2010, 92:679-686. 10.1302/0301-620x.92b5.22941

26. Giannotti S, Bottai V, Dell'Osso G, De Paola G, Ghilardi M, Guido G: Pseudoarthrosis in atypical femoral fracture: case report. Osteoporos Int. 2013, 24:2893-2895. 10.1007/s00198-013-2397-3

27. Weil YA, Rivkin G, Safran O, Liebergall M, Foldes AJ: The outcome of surgically treated femur fractures associated with long-term bisphosphonate use. J Trauma. 2011, 71:186-190. 10.1097/TA.0b013e31821957e3

28. Bonifacio L, Syson P: Construct failure in an atypical femoral fracture treated with intramedullary nailing: a case report. Malays Orthop J. 2014, 8:82-84. 10.5704/MOJ.1403.008

29. Visekruna M, Wilson D, McKiernan FE: Severely suppressed bone turnover and atypical skeletal fragility . J Clin Endocrinol Metab. 2008, 93:2948-2952. 10.1210/jc.2007-2803

30. Schilcher J, Sandberg O, Isaksson H, Aspenberg P: Histology of 8 atypical femoral fractures: remodeling but no healing. Acta Orthop. 2014, 85:280-286. 10.3109/17453674.2014.916488 